\title{
The effect of lactose-in-saline infusion on packed cell volume variation during trypanosoma vivax - induced anaemia of cattle
}

\author{
I. A. Umar ${ }^{1 \star}$, I. O. Igbokwe' ${ }^{2}$, J. J. Omage ${ }^{3}$, D. A. Ameh ${ }^{1}$, H. O. Kwanashie ${ }^{4}$ and K. A. N. Esievo ${ }^{5}$ \\ ${ }^{1}$ Department of Biochemistry, Ahmadu Bello University Zaria, Nigeria, \\ ${ }^{2}$ Department of Veterinary Pathology, University of Maiduguri, Maiduguri, Nigeria. \\ ${ }^{3}$ Department of Animal Science, Ahmadu Bello University, Zaria, Nigeria. \\ ${ }^{4}$ Department of Pharmacology, Ahmadu Bello University, Zaria, Nigeria. \\ ${ }^{5}$ Department of Veterinary Pathology and Microbiology, Ahmadu Bello University Zaria, Nigeria.
}

Accepted 21 March, 2008

\begin{abstract}
The effect of intravenous infusion of a solution of lactose-in-normal saline on the course of Trypanosoma vivax induced anaemia in Zebu yearlings was investigated. The animals were infected with $11 \times 10^{6}$ trypanosomes by jugular venipuncture and lactose-in-normal saline infusion started on day 6, post-infection (p.i). Three four-hourly doses of $0.5 \mathrm{~g}$ lactose $/ \mathrm{kg}$ body weight were administered to each infected yearling in the experimental group daily for five days, while the infected control yearlings received no lactose-infusion. The experiment was terminated on day 13 , p.i. Parasitaemia in the lactoseinfused yearlings was scorable throughout the duration of experiment while parasites could not be detected in the blood of the infected control yearlings between days 7 and 9, p.i. Serum free sialic acids (FSA) concentration was also consistently higher in the lactose-infused yearlings than in the lactosefree ones. In the before lactose infusion (BL) period the PCV of the lactose-infused group dropped at a significantly $(P<0.05)$ faster rate than in the lactose-free one. In the $D L$ (during lactose infusion) period, the rate and magnitude of decline in PCV was significantly lower in the lactose-infused yearlings than in the lactose-free animals. When lactose infusion was stopped (AL) the rate and magnitude of PCV decline became greater in the lactose-infused yearlings than in the lactose-free ones. It was thus concluded that lactose ameliorated anaemia, by inhibiting the sequestration of desialylated erythrocytes from the blood stream of $T$. vivax-infected yearlings. This manifested in the reduced magnitude and rate of decrease in PCV in the lactose-infused infected yearlings.
\end{abstract}

Key words: Trypanosoma vivax, trypanosomosis, anaemia, lactose, erythrophagocytosis.

\section{INTRODUCTION}

The presence of membrane-bound sialidase (neuraminidase; EC 3.2.1.18) on several species of trypanosomes has been severally reported by researchers. The enzyme has been demonstrated and characterized in Trypanosoma brucei, Trypanosoma congolense and Trypanosoma b. rhodensiense (Engstler et al., 1993, 1995; Nok and Uemura, 1998). Trypanosoma vivax was first shown to express sialidase activity in vitro and in vivo in 1979

\footnotetext{
${ }^{*}$ Corresponding author. E-mail: smaumar@yahoo.com. Tel: +234-802-3586896.
}

(Esievo, 1979, 1980) and the enzyme was recently fully characterized (Buratai et al., 2004). Trypanosomal sialidases have been implicated in the pathophysiology of trypanosomal infections, particularly tissue-invasion and development of anaemia (Esievo et al., 1982; Esievo and Saror, 1991; Schenkman and Eichinger, 1993).

Anaemia is the most prominent and disease-promoting feature of trypanosomal infections and some factors have been implicated in the aetiology; the principal of which is erythrophagocytosis. Erythrophagocytosis requires the initial removal of the sialic acid coat of red blood cells (Muller et al., 1981,1983) and this enhances the rate and strength of binding of the desialylated erythrocytes to the 
B-D-galactose-specific lectins on the surfaces of macrophages (Kelm et al., 1986a), thereby leading to increased erythrophagocytosis in vitro and sequestration from the blood stream in vivo. It has been demonstrated that development of anaemia during trypanosomosis is linked to desialylation of erythrocytes by trypanosomal sialidases (Esievo et al., 1982, 1994; Umar et al., 2003) as well as enhanced binding and subsequent sequestration of the damaged erythrocytes by Kupffer cells (and other cell types) of the expanded mononuclear phagocytic system (Ibrahim et al., 2005).

Erythrophagocytosis is a two-step process involving an initial, rate-limiting step of binding of the desialylated erythrocyte to $\beta$-D-galactose-specific lectins on macrophages and a subsequent phagocytic step which requires some serum complement substances (Muller et al., 1983; Kelm et al., 1986b; Kuster and Schauer, 1981). The ratelimiting binding step is inhibited both in vitro (SchlepperSchafer et al., 1980) and in vivo (Muller et al., 1981) by galactose and $\beta$-glycosidically bound $\beta$-D-galactosyl residues; and lactose has been specifically shown to have this inhibitory effect. Thus it is reasonable to expect that lactose would be able to slow down the rate of erythrophagocytosis during trypanosomosis and consequently reduce the rate at which anaemia develops in the disease. It is instructive to note that the trypanotolerant N'dama breed of cattle has erythrocyte-surface sialic acids that are resistant to hydrolysis by sialidases (Esievo et al., 1986,1990; Shugaba et al., 1994) and hence less prone to erythrophagocytosis. It is suggested that the use of lactose (as an excipient for a trypanocidal agent) may improve the efficacy and efficiency of treatment by slowing down the rate of development of anaemia, and hence the general degeneration of the infected animal. Earlier investigations have established the plasma kinectics of infused lactose-in-saline in apparently healthy (Umar et al., 1998a) and T. vivax-infected cattle (Umar et al., 1998b), as well as the effect of the infusion on electrolyte balance in these animals (Kadima et al., 1999). The present report focuses on the variations in packed cell volumes, as an index of anaemia, in T. vivaxinfected cattle infused with lactose-in saline solution.

\section{MATERIALS AND METHODS}

\section{Experimental animals and treatment}

Fourteen male Zebu (Sokoto Gudali) yearlings, aged $12-18$ months and weighing $80-90 \mathrm{~kg}$ were purchased from a tsetse (Glossina sp.) - free area (Talata Mafara, Sokoto State, Nigeria). The animals were acclimatized for 3 weeks, during which period they were dewarmed, de-ticked and vaccinated as described elsewhere (Umar et al., 1998a,b).

The yearlings were divided into four groups at random and housed separately. The 3 yearlings in Group 1 were maintained as normal healthy controls to generate base-line data. The Group 2 animals (4 yearlings) were not infected but received 3 daily intravenous doses of $0.5 \mathrm{~g}$ lactose per $\mathrm{kg}$ body weight at four-hourly intervals for 5 days, coinciding with the period of lactose infusion in the animals in Group 4. Groups 3 and 4 animals ( 3 and 4 yearlings, respectively) were infected with $11 \times 10^{6} \mathrm{~T}$. vivax (Samaru stock) as described by Umar et al. (1998b). Lactose administration to animals in Group 4 commenced on day 6, post-infection (p.i.), as described for Group 2 animals, when the disease had established as indicated by peak parasitaemia and associated decline in packed cell volume (PCV). Lactose administration was terminated on day 10, p.i., and the experiment on day 13 , p.i.

\section{Preparation of lactose solution}

A $50 \%$ solution of lactose was prepared in physiological saline, treated and administered as earlier described (Umar et al., 1998a, b).

\section{Trypanosome infection}

The source and treatment of the T. vivax (Samaru stock) used in this work have been described elsewhere (Umar et al., 1998b).

\section{Sampling and analyses}

Two (2) $\mathrm{ml}$. of jugular blood was collected at $0900 \mathrm{hr}$. daily into EDTA-tubes, and $3 \mathrm{ml}$ into plain tubes for preparation of serum, for the assay of free sialic acids by the method of Aminoff (1961). Parasitaemia was monitored daily by the microhaematocrit method (Woo, 1969) and scores were given as $1+$ (occasional trypanosome in the buffy coat area), 2+ (1 - 2 trypanosomes), $3+(3-20$ trypanosomes) and $4+$ (20 or more trypanosomes). At high parasitaemia, tryapanosomes were also counted using the new improved Neubauer haemocytometre. Packed cell volume was determined by the microhaematocrit method.

\section{Analysis of data}

The variation in PCV values of both infected groups were analyzed in time series consisting of 3 distinct periods; before (BL) during $(\mathrm{DL})$ and after $(\mathrm{AL})$ lactose infusion. The daily percentage change $(\mathrm{X} \%)$ in PCV values for each yearling was calculated as follows:

$$
\mathrm{X}_{\mathrm{i}} \%=\frac{\mathrm{PCV}_{\mathrm{t}}-\mathrm{PCV}_{\mathrm{t}-1}}{\mathrm{PCV}_{\mathrm{t}-1}} \mathrm{X} 100
$$

Where, $P C V_{t}$ is the PCV value for any given day, t, while $P C V_{t-1}$ is the value for the preceding day. The mean percentage change in PCV, $\bar{X}$, for each day was calculated:

$$
\bar{X}=\frac{\sum X i \rightarrow n}{n}
$$

Where, $X i \rightarrow n$ are the calculated percentage changes for the yearlings in the group and $n$ is the number of yearlings in the group. The mean cumulative percentage (CPC) in each group was separately calculated for each of the 3 designated periods (that is, $B L, D L$ and $A L)$ :

$$
C P C=\frac{\sum(X i \rightarrow n)^{d 1 \rightarrow t}}{n \times d t}
$$




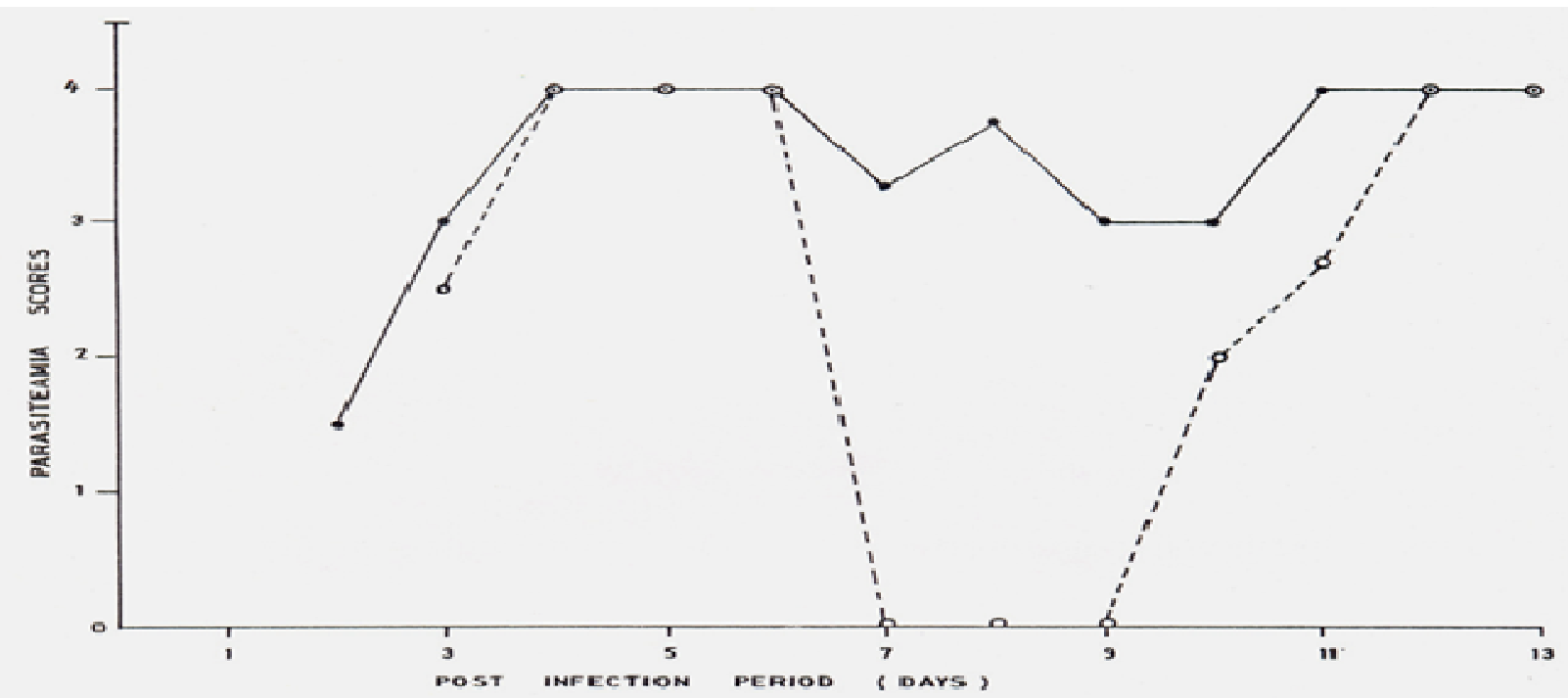

Figure 1. Profiles of parasitaemias of $T$. vavax infected cattle treated $(\bullet)$ and untreated $(\#)$ with lactose

Where, $(X i \rightarrow n)^{d 1 \rightarrow t}$ are the calculated percentage changes for the yearlings in the group for the first day through to the last day for the designated period; $d t$ is the number of days that constitute the designated period.

The difference ( $\triangle P C V$ ) between a given $\mathrm{PCV}$ value, $\mathrm{PCV}_{\mathrm{t}}$, and that on the day of commencement of the given period, $\mathrm{PCV}_{\mathrm{a}}$, (that is, $P C V_{a}$ for $B L$ was the PCV on day 0 , for $D L$ was that on day 6 , p.i. and for $A L$ was that on day 10 p.i.), is given by:

$$
\triangle P C V=P C V_{t}-P C V_{t-1}
$$

The mean differences, $\overline{\triangle P C V}$, for the group was calculated:

$\overline{\Delta P C V}=\frac{\sum \Delta P C V i \rightarrow n}{n}$

Cumulative sums of difference, $\mathrm{C}_{\mathrm{t}}$, from $\mathrm{PCV}_{\mathrm{a}}$ (for the specific period) was calculated from the mean differences for each day:

$$
C_{t}=\overline{\Delta P C V}_{t}-\overline{\Delta P C V}_{t-1}
$$

Where, $\overline{\triangle P C V}_{t}$ and $\overline{\triangle P C V}_{t-1}$ are the mean differences for given day, $\mathrm{t}$, and the previous day, respectively.

The rate of change in PCV for the periods, BL, DL and $A L$ in the two infected groups was assessed by first plotting the $C_{t}$ values against Time (in days) and fitting a regression line (Chatfield, 1983). Then the theoretical mean differences from $\mathrm{PCV}_{\mathrm{a}}$ during the designated periods were estimated by drawing perpendicular lines from the Time-axis to intercept the $C_{t}$ regression line and the $C_{t}$ values extrapolated from the $\mathrm{C}_{\mathrm{t}}$-axis. The rate of change in $\mathrm{PCV}$ was calculated as the theoretical $C_{t}$ value (from the plot) divided by Time (days) and expressed as Units Day ${ }^{-1}$. The calculated rates of change in PCV were plotted against Time (days).

All data were summarized as means \pm Standard Error of Means (SEM) and comparison between two means was done using the standard Students' t-test.

\section{RESULTS}

\section{Parasitaemia}

The profiles of the daily mean parasitaemia scores of both infected groups are presented in Figure 1. Parasitaemia in Group 4 was detected a day earlier than in Group 3 but it peaked on the same day 6 p.i. in both groups. Lactose infusion in Group 4 was started on this day, parasitaemia score in this group started to decline to reach the lowest recorded score on day 9 , after which it again rose starting the second parasitaemic wave. In Group 3 (uninfused), however, parasitaemia was too low to be detected in the blood between days 7 and 9, p.i. The second parasitaemic wave in this group started on day 10 , p.i.

The mean trypanosome counts at the first parasitaemic peak (day 6, p.i.) were $2.20 \pm 0.46$ and $1.70 \pm 0.45 \times 10^{7}$ parasites $/ \mathrm{ml}$ of blood for Groups 3 and 4, respectively. At the termination of experiment (day 13, p.i.) the mean trypanosome counts for Groups 3 and 4 were $0.90 \pm 0.17$ and $1.40 \pm 0.40 \times 10^{7}$ parasites $/ \mathrm{ml}$ of blood, respectively. At both peaks the parasitaemias of the two groups were statistically similar $(P>0.05)$.

\section{Serum free sialic acids (FSA)}

The rise in mean serum FSA concentrations coincided with the increase in parasitaemia in both groups and declined with fall in parasitaemia (Figure 2). The level of serum FSA in Group 3 yearlings returned to pre-infection values on the day when parasites could not be detected in the blood (day 7, p.i.). In the lactose-infused, infected yearlings (Group 4), however, the serum FSA never returned to the pre-infection level throughout the period of 


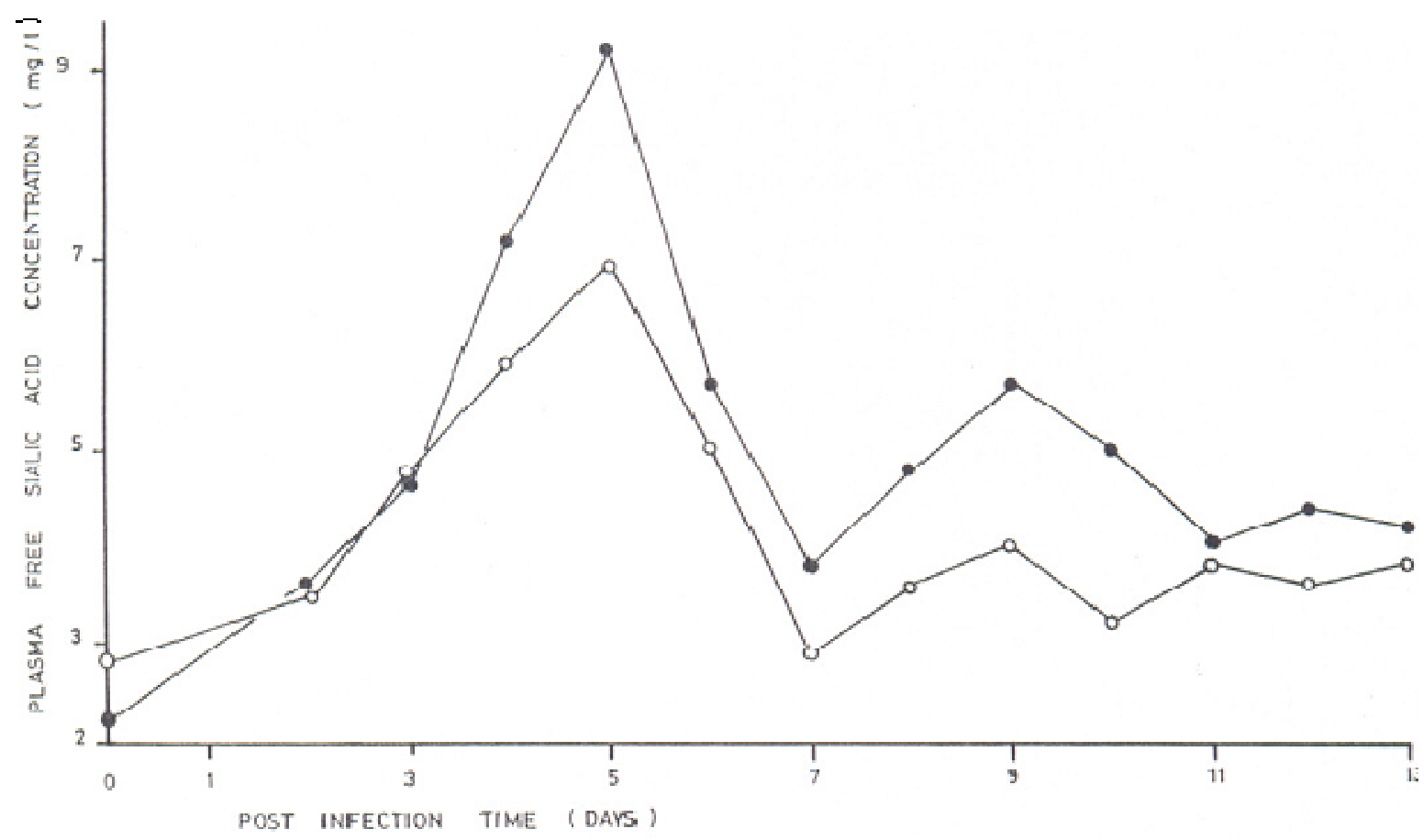

Figure 2. Profiles of plasma free sialic acid concentrations in $T$. vivax infected cattle treated $(\bullet)$ and untreated $(\#)$ with lactose.

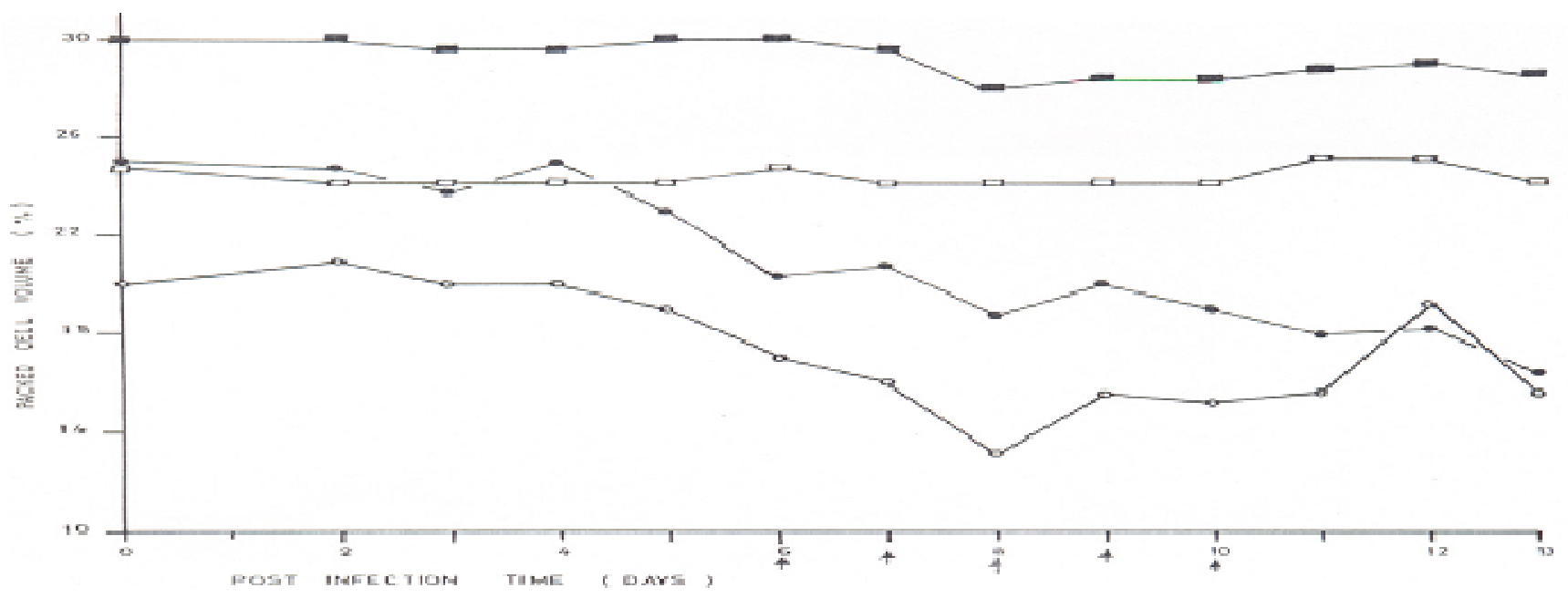

Figure 3. Profiles of PCV healthy cattle treated $(\varsigma)$ or untreated $(\square)$ with lactose and of $T$. vivax infected cattle treated $(\bullet)$ and untreated $(\neg)$ with lactose. Arrow indicate days when lactose was infused in the lactose treated groups.

the experiment.

The mean peak serum FSA concentrations for both groups of infected yearlings were recorded on day 5, p.i. and the value of $9.20 \pm 0.74 \mathrm{mg} \mathrm{L}^{-1}$ recorded for the Group 4 animals was significantly $(P<0.05)$ higher than the $6.92 \pm 0.49 \mathrm{mg} \mathrm{L}^{-1}$ recorded for Group 3 yearlings. In the two healthy groups no significant fluctuations were recorded in their serum FSA concentrations.

\section{Packed cell volume (PCV)}

The PCV profiles for all four groups of yearlings are presented in Figure 3 . The fluctuations in PCV for the normal controls (Group 1) were within a narrow, insignificant range throughout the experiment, and the same was true for the healthy, lactose-infused yearlings (Group 2) until lactose infusion commenced, during which 
Table 1. The daily mean percentage change and mean cummulative percentage changes (CPC) in PCV of $T$. vivax Infected Zebu cattle before (BL), during (DL) and after $(A L)$ lactose infusion.

\begin{tabular}{|c|c|c|c|c|c|c|c|c|c|c|c|c|c|c|c|}
\hline \multirow[b]{3}{*}{ Post-infection time (days) } & \multicolumn{15}{|c|}{ Mean percentage changes in PCV (\%) } \\
\hline & \multicolumn{5}{|c|}{ BL } & \multirow[t]{2}{*}{ CPC } & \multicolumn{4}{|c|}{ DL } & \multirow[t]{2}{*}{ CPC } & \multicolumn{3}{|c|}{ AL } & \multirow[t]{2}{*}{ CPC } \\
\hline & 2 & 3 & 4 & 5 & 6 & & 7 & 8 & 9 & 10 & & 11 & 12 & 13 & \\
\hline Uninfused Infected & +8.3 & -4.5 & -3.3 & -3.3 & -10.5 & -13.3 & -6.3 & -17.2 & +18.6 & -1.8 & -7.5 & +2.6 & +24.9 & +19.1 & +8.4 \\
\hline Group $(n=3)$ & $\pm 1.7^{\mathrm{a}}$ & \pm 2.6 & $\pm 1.6^{\mathrm{a}}$ & $\pm 2.4^{\mathrm{a}}$ & \pm 0.5 & \pm 5.1 & $\pm 3.6^{\mathrm{a}}$ & $\pm 4.9^{\mathrm{a}}$ & $\pm 4.6^{\mathrm{a}}$ & \pm 0.5 & $\pm 2.9^{\mathrm{a}}$ & $\pm 1.6^{\mathrm{a}}$ & $\pm 9.7^{\mathrm{a}}$ & $\pm 2.0^{\mathrm{a}}$ & $\pm 2.0^{\mathrm{a}}$ \\
\hline Infused Infected & -3.0 & -4.0 & +5.6 & -8.0 & -10.0 & -19.5 & +1.7 & -3.2 & +5.5 & -4.0 & +0.01 & -5.4 & -1.6 & -9.4 & -13.2 \\
\hline Group (n=4) & $\pm 1.0^{\mathrm{b}}$ & \pm 1.6 & $\pm 1.4^{b}$ & $\pm 2.3^{b}$ & \pm 2.9 & \pm 4.8 & $\pm 0.9^{b}$ & $\pm 1.3^{\mathrm{b}}$ & $\pm 0.6^{b}$ & \pm 3.2 & $\pm 0.2^{b}$ & $\pm 2.3^{b}$ & $\pm 2.7^{\mathrm{b}}$ & $\pm 2.3^{b}$ & $\pm 2.2^{b}$ \\
\hline
\end{tabular}

All values are Mean \pm SEM. Negative and positive signs indicate decreases and increases, respectively. Comparison was done between the two groups and values with different superscripts $(a, b)$ are statistically different $(P<0.05)$.

$\mathrm{BL}=$ Before lactose infusion.

$\mathrm{DL}=$ During lactose infusion.

$\mathrm{AL}=$ After lactose infusion.

$\mathrm{CPC}=$ Cummulative Percentage Change

period a cumulative mean percentage fall in PCV of $4.31 \pm 3.2 \%$ was recorded. The more significant PCV changes in the two T. vivax-infected groups of yearlings were analyzed in time series: with changes in PCV between days 0 and 6 p.i. (BL), days 7 and 10, p.i. (DL) and days 11 and 13, p.i. (AL) analyzed separately.

\section{PCV changes before lactose infusion (BL)}

The PCV of the infected, lactose-infused yearlings (Group 4) recorded a mean decrease of $3.0 \pm$ $1.0 \%$ two days after infection, while that of the infected, uninfused control yearlings (Group 3) increased by a mean $8.3 \pm 1.7 \%$ on the same day (Table 1). On subsequent days the PCV in the two groups gradually dropped until mean percentage decreases of $10.5 \pm 0.5$ and $10.0 \pm 2.9 \%$ were recorded on day 6, p.i. for Groups 3 and 4, respectively. The Group 4 animals recorded a higher, though insignificant $(P>0.05)$, cumulative mean percentage decrease in PCV (Table 1) than did animals in Group 3, over this BL period. The
$\mathrm{C}_{\mathrm{t}}$ profile for Group 4 yearlings for the period BL (Figure $4-\mathrm{BL}$ ) tended to confirm this observation since it was situated below that of the Group 3 animals. Furthermore, the profile of rates of change in PCV for Group 4 over the same period (Figure $5-\mathrm{BL}$ ) was more negative than that of Group 3, indicating a greater rate of decrease in PCV in Group 4 animals. The PCV in Group 4 yearlings was falling at a mean rate of $0.56 \pm 0.14$ Units Day $^{-1}$ over this period (Table 2), this response was significantly $(P<0.05)$ different from that in Group 3.

\section{PCV changes during lactose infusion (DL)}

Administration of lactose to Group 4 yearlings commenced on day 6 , p.i. when the disease had established, and was stopped on day 10 , p.i. On day 7, p.i. the mean PCV in Group 4 improved by $1.7 \pm 0.9 \%$, while that for Group 3 further dropped by $6.3 \pm 3.6 \%$ (Table 1 ). Over this period the cumulative percentage changes (CPC) in PCV (Table 1) were $+0.01 \pm 0.2$ and $-7.5 \pm 2.9 \%$ for
Group s 4 and 3, respectively. These values were statistically different $(P<0.05)$. The $C_{t}$ regression line for Group 4 yearlings (Figure $4-\mathrm{DL}$ ) was displaced upwards, above that for Group 3 yearlings. This indicated that the decrease in PCV during this period was considerably reduced in Group 4 animals as illustrated by the profiles in Figure 5 $\mathrm{DL}$, which showed the graph of rate of change in PCV for Group 3 being values were statistically different $(P<0.05)$ higher in Group 3 than in Group 4.

\section{PCV changes after lactose infusion ( $A L)$}

On day 11, p.i. the PCV of Group 4 yearlings recorded a mean drop of $5.4 \pm 2.3 \%$ (Table 1) from the value for the previous day, while Group 3 animals recorded an increase in PCV. The CPC in PCV (Table 1) for this period, for Groups 3 and 4 , were $+8.4 \pm 2.0$ and $-13.2 \pm 2.2 \%$, respectively. These changes were signifi-cantly $(P<0.05)$ different. The $C_{t}$ profiles for this period (Figure $4-$ $\mathrm{AL}$ ) showed that of Group 4 being below that of 


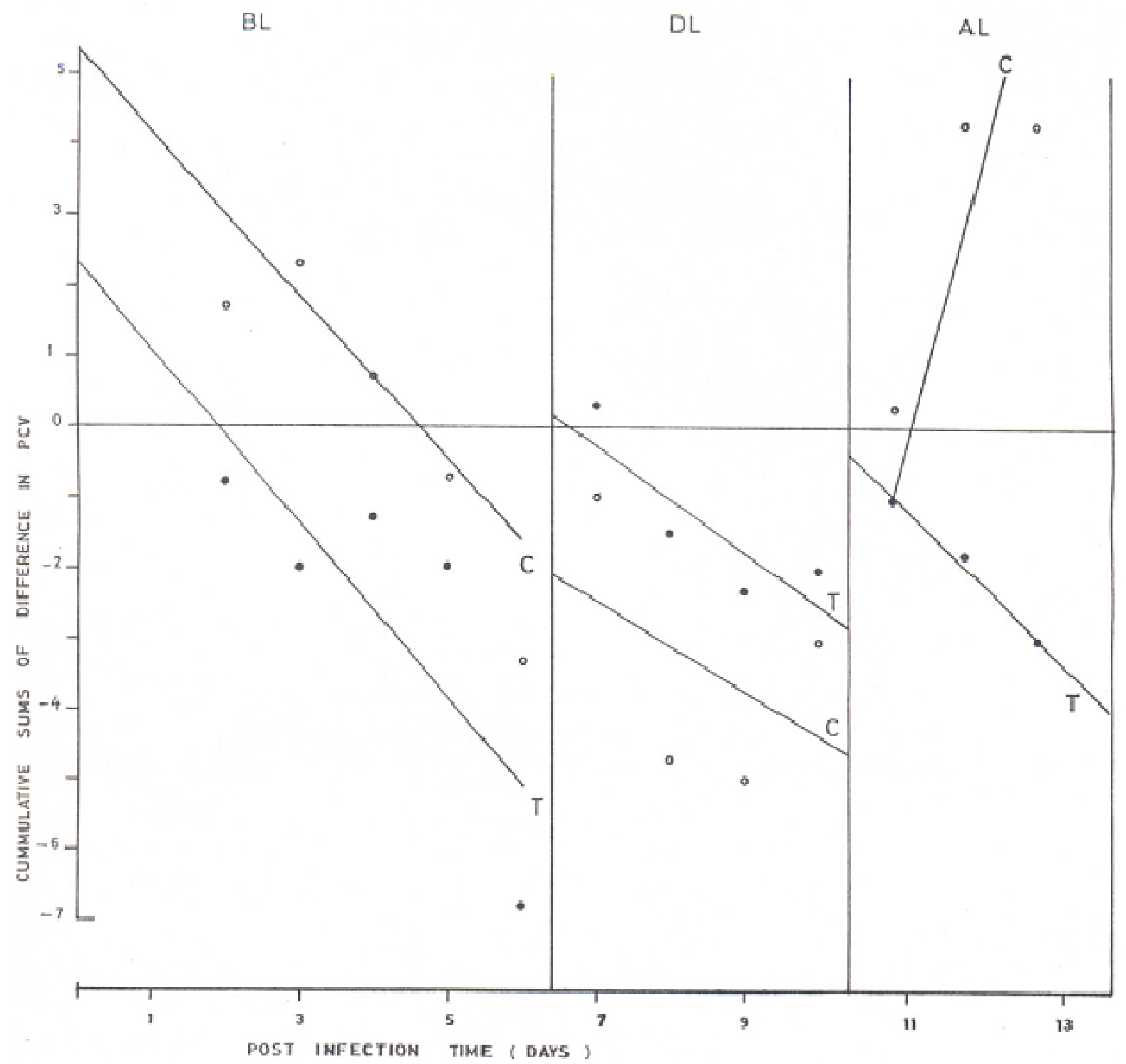

Figure 4. Profiles of cumulative sums of difference $\left(C_{t}\right)$ in PCV of $T$. vivax infected cattle treated $(T)$ and untreated (C) with lactose, before (BL), during (DL) and after ( $A L$ ) lactose treatment.

Group 3, the same pattern was observed for the profiles of rates of change in PCV (Figure $5-A L$ ). These observations indicated a greater magnitude and rate of decrease in PCV for Group 4 than Group 3. The mean rates of change in PCV (Table 2) indicated that the PCV of Group 4 yearlings was dropping at a significantly $(\mathrm{P}<$ $0.05)$ faster rate than that of Group 3 yearlings over this period.

\section{DISCUSSION}

Parasitaemia in Group 4 yearlings was detectable and scorable throughout the period of infection, while in Group 3 parasites could not be detected in the blood between days 7 and 9 , p.i. This indicated that lactose sustained the parasites in the blood of the lactose-infused Group 4 yearlings. Perhaps lactose in some way interfered with the host's capacity to destroy the parasite. More probable, however, is the possibility that the parasites were able to utilize lactose as an additional source of metabolic energy. It is conceivable that lactose induced the production of $\beta$-galactosidase (an enzyme needed for lactose catabolism by micro-organisms) by the protozoan parasite in much the same way it does in bacteria. An additional source of metabolic energy may have stimulated increased proliferation of the parasite in the blood, out-stripping the rate of destruction.

The levels of serum FSA in both infected groups rose with increasing parasitaemia. T. vivax had been shown to 


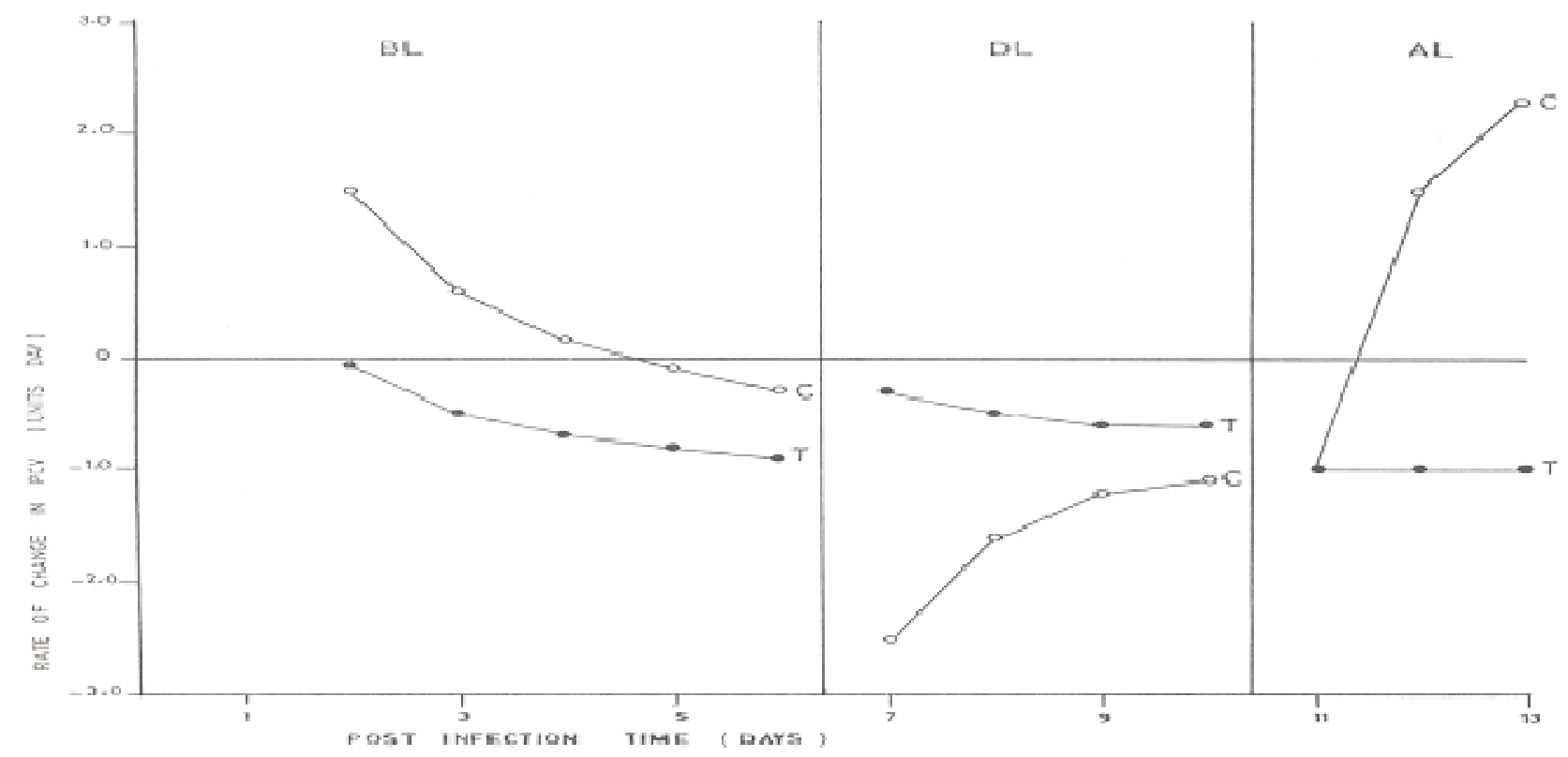

Figure 5. Profiles of rates of change in PCV of $T$. vivax infected cattle treated $(T)$ and untreated $(C)$ with lactose, before (BL), during $(D L)$ and after $(A L)$ lactose treatment.

Table 2. Mean rates of change in PCV of $T$. vivax-infected Zebu cattle before (BL), during $(\mathrm{DL})$ and after $(\mathrm{AL})$ lactose infusion.

\begin{tabular}{|c|c|c|c|}
\hline \multirow{2}{*}{ Group } & \multicolumn{3}{|c|}{ Rate of change in PCV (Units Day ${ }^{-1}$ ) } \\
\cline { 2 - 4 } & BL & DL & AL \\
\hline Uninfused Infected Group $(\mathrm{n}=4)$ & $+0.38 \pm 0.32^{\mathrm{a}}$ & $-1.60 \pm 0.32^{\mathrm{a}}$ & $+0.93 \pm 0.99^{\mathrm{a}}$ \\
Infused Infected Group $(\mathrm{n}=4)$ & $-0.56 \pm 0.14^{\mathrm{b}}$ & $-0.51 \pm 0.08^{\mathrm{b}}$ & $-0.97 \pm 0.06^{\mathrm{b}}$ \\
\hline
\end{tabular}

All values are Mean \pm SEM. Negative and positive signs indicate rates decreases and increases, respectively. Comparison was done between the two groups and values with different superscripts $(a, b)$ are statistically different $(P<0.05)$

produce sialidase (Esievo, 1979; 1983) which cleaves erythrocyte surface sialic acids during experimental infection of cattle (Esievo et al., 1982). The progressive increase in serum FSA in the two infected groups was indicative of increasing activity of trypanosomal sialidase; more so when similar increases in serum FSA were not apparent in the two healthy groups of yearlings. Furthermore, in vitro sialidase activity of $T$. vivax had been shown to be directly proportional to the number of parasites (Esievo, 1979, 1983). The significantly higher peak serum FSA concentration recorded in the Group 4 animals may be partly due to the earlier appearance of parasites in the blood of these animals, and partly due to higher parasitaemia recorded.

The anaemia in both groups of infected yearlings started to develop during the first parasitaemic wave, conforming to the established pattern for trypanosome infection. During the first of the 3 distinct periods of the experiment (that is, BL) the rate and magnitude of decrease in PCV for Group 4 yearlings were higher than for Group 3 yearlings. This may be associated with the earlier appearance of parasitaemia in the Group 4 animals, since the onset and severity of the anaemia in trypanosome infections are directly related to the appearance and level of the initial parasitaemias (Dargie et al., 1979a,b; Esievo et al., 1982).

The pattern of PCV decrease in the infected yearlings in Group 4 was modified by lactose infusion. Lactose considerably reduced the rate and magnitude of PCV decrease so much that it was overtaken by that of the Group 3 yearlings. This is even more significant considering that this period (DL) coincided with the time parasites could not be detected in Group 3 yearlings, while parasitaemia was still scorable, and sialidase activity still relatively high in Group 4 yearlings. It is reasonable, therefore, to surmise that lactose had reduced the rate of development and degree of anaemia in Group 4 yearlings. This was attributed to the role of lactose in preventing the sequestration of desialylated red blood cells (RBCs) from the blood stream by cells of the 
expanded and activated mononuclear phagocytic system. Trypanosomal sialidases (Esievo, 1979, 1980; Pereira, 1983; Pereira and Hoff, 1986; Engstler et al., 1991; Engstler and Schauer, 1993; Umar et al., 2003; Buratai et al., 2004) desialylate RBCs and hosts cells (Esievo et al., 1982; Pereira and Hoff, 1986). These desialylated RBCs bind to $\beta$-D-galactose-specific lectins on the surface of macrophages (Kuster and Schauer, 1981; Muller et al., 1983) and are subsequently phagocytised. In the blood stream such RBCs are also rapidly sequestrated (Durocher et al., 1975; Aminoff et al., 1977; Jancik et al., 1978; Muller et al., 1981). Thus during the course of the $T$. vivax infection in this experiment the trypanosomal sialidase produced increased with parasitaemia and hence more sialic acids were removed from the surfaces of RBCs, as evidenced by the steady rise in the level of serum FSA, during the first parasitaemic wave. Rapid sequestration of these desialylated RBCs would lead to the observed fall in PCV. $\beta$-Glycosidically linked $\beta$ galactoside residues had however been shown to inhibit the rate-limiting binding step of the erythrophagocytic process in vitro (Kolb and Kolb-Bachofen, 1978; Nagamura and Kolb, 1979; Kolb et al., 1980), thus preventing erythrophagocytosis. Lactose had specifically been shown to perform this inhibitory role in vitro (Kelm and Schauer, 1986; Kelm et al., 1986a) and in vivo (Muller et al., 1981). A recent report (Ibrahim et al., 2005) showed that lactose inhibited in vitro binding and phagocytosis of desialylated RBCs from $T$. vivax-infected goats by homologous isolated liver kupffer cells. The same report showed that the in vitro binding and phagocytosis of desialylated RBCs from $T$. vivax-infected cattle by homologous liver Kupper cells isolated from the lactose-infused cattle were significantly less than observed with kupffer cells from cattle infused with lactose.

Thus, the lactose in the circulation of the infected Group 4 yearlings prevented, or at least reduced, the binding (and hence sequestration) of the desialylated RBCs in circulation, thereby prolonging their life span. This manifested as a considerably reduced rate of decrease in PCV during the period of lactose infusion.

The immediate and vigorous resumption of decrease in PCV of the Group 4 yearlings soon after termination of lactose infusion further supports the conclusion that lactose played a significant role in the observed retardation of PCV decline during lactose infusion. The rapid decline in PCV in this period may be attributed to the fact that during lactose infusion sequenstration of desialylated RBCs was inhibited and so they accumulated in the blood stream. As soon as inhibition was removed sequestration of the accumulated desialylated RBCs resumed with vigour.

In conclusion, because the lactose infusion could reduce the rate of $\mathrm{PCV}$ in the infected yearlings, this study has provided a corroborating evidence that desialylation of erythrocytes is a mechanism of erythrocyte injury in the early acute phase of $T$. vivax infection as earlier suggested by Esievo et al. (1982).

\section{ACKNOWLEDGEMENTS}

The financial support from Ahmadu Bello University Board of Research EEC Lome III Trypanosomiasis Project in Nigeria is highly appreciated. The assistance of A. Adaji, A. Olonitola, A. Sunday and G. Aka'a is also appreciated.

\section{REFERENCES}

Aminoff D (1961). Methods for the quantitative estimation of $\mathrm{N}$-acetylneuraminic acid and their application to hydrolysis of sialomucoids. Biochem. J. 81: 384-392.

Aminoff D, Vorder-Bruegge WF, Bell WC, Sarpolis K, Williams R (1977). Role of sialic acid in survival of erythrocytes in the circulation: Interaction of neuraminidase treated and untreated erythrocytes with spleen and liver at the cellular level. Proc. Nat. Acad. Sci., 74: 15211524.

Buratai LB, Nok AJ, Ibrahim S, Umar IA, Esievo KAN (2004). Characterization of sialidase from blood-stream forms of $T$. vivax. Cell Biochem. Funct., 24: 71-77.

Chatfield C (1983). Statistics for Technology. A course in Applied statistics. $3^{\text {rd }}$. Ed. Chapman and Hall, London, pp. 191-194.

Dargie JD, Murray PK, Murray M, Grimshaw WHT, McIntyre WIM (1979a). Bovine trypanosomiaisis: the red cell kinetics of N'dama and Zebu cattle infected with Trypanosoma congolense. Parasitol., 78: 271-286.

Dargie JD, Murray PK, Murray M, McIntyre WIM (1979b). The blood volumes and erythrokinetics of N'dama and Zebu cattle experimentally infected with Trypanosoma brucci. Res. Vet. Sci., 26: 245-247.

Durocher JR, Payne RC, Conrad ME (1975). Role of sialic acid in erythrocyte survival. Blood 45: 11-20.

Engstler M, Reuter G, Schauer R (1991). Partial purification and characterization of a sialidase from T. brucei. Glycoconjugate J., 8 : 269.

Engstler M, Reuter G, Schauer R (1993). The developmentally regulated trans-sialidase from $T$. brucei sialylates PARP. Mol. Biochem. Parasitol., 61: 1-14.

Engstler M, Schauer R (1993). Sialidases from African trypanosomes. Parasitol. Today, 9(6): 222-225.

Engstler M, Schauer R, Brun R (1995). Distribution of developmentally regulated trans-sialidase in kinetoplastida and characterization of a shed trans-sialidase from T. congolense. Acta Tropica, 59: 117-129.

Esievo KAN (1979). In vitro production of neuraminidase (sialidase) by T. vivax. Proceedings of the $16^{\text {th }}$ meeting of the OAU/STRC International Council for trypanosomiasis research and control. Yaounde, Cameroon, October 29 - November 3. pp. 205-210.

Esievo KAN (1980). Studies on an aspect of the anaemia of bovine trypanosmiasis (T. vivax). Ph.D. thesis. Ahmadu Bello University, Zaria, Nigeria.

Esievo KAN (1983). T. vivax, stock V953: inhibitory effect of a type A influenza virus anti-HAV8 serum on in vitro neuraminidase (sialidase) activity. J. Parasitol., 69: 491-495

Esievo KAN, Jaye A, Andrew JN, Ukoha AI, Alafiatayo RA, Eduvie LO, Saror DI, Njoku CO (1990). Electrophoresis of bovine erythrocyte sialic acids: existence of additional band in trypanotolerant N'dama cattle. J. Comp. Pathol., 102: 357-361.

Esievo KAN, Saror DI, Kolo MN, Eduvie LO (1986). Erythrocyte surface sialic acid in N'dama and Zebu cattle. J. Comp. Pathol., 96: 95-99.

Esievo KAN, Saror DI (1991). Immunochemistry and immuno-pathology of animal trypanosomiasis. Vet. Bull., 61: 765-777.

Esievo KAN, Saror DI, llemobade AA, Hallaway MH (1982). Variation in erythrocyte surface and free serum sialic acid concentrations during experimental $T$. vivax infection in cattle. Res. Vet. Sci., 32: 1-5. 
Esievo KAN, Omage JJ, Ibrahim NDG, Umar IA, Saror DI (1994). Role of lactose in the control of cattle trypanosomiasis. VIth Congress of the International Society for Animal Clinical Biochemistry, August, 26, Guelph, Ontario, Canada, pp. 137.

Ibrahim NDG, Esievo KAN, Umar IA (2005). The effects of lactose on the pathological manifestations of Trypanosoma vivax infection in cattle. Niger. Vet. J., 26(1): 25-33.

Jancik JM, Schauer R, Andres KH, During M (1978). Sequestration of neuraminidase - treated erythrocytes: studies on its topographic morphologic and immunologic aspects. Cell Tissue Res., 186: 209229.

Kadima K B, Umar IA, Omage JJ, Igbokwe IO, Ibrahim NDG, Gyang E O, Saror D I, Esievo KAN (1999). Effects of lactose in saline infusion on electrolyte alterations in T. vivax infected cattle. J. Clin. Biochem. Nutr., 27: 27-36.

Kelm S, Shukla A K, Paulson J C, Schauer R (1986b). Reconstitution of the masking effect of sialic acid groups on sialidase treated erythrocytes by the action of sialyltransferase. Carbohydr. Res., 149: 59-64.

Kelm S, Schauer R (1986). The galactose-recognising system of rat peritoneal macrophages: Receptor-mediated binding and uptake of glycoproteins. Biological Chemistry Hoppe-Seyler's, 367: 989-998.

Kelm S, Jibril SD, Lee H, Yoshino T, Schauer R (1986a). The galactose receptor of rat - peritoneal macrophages binding to sialidase treated blood cells and glycoproteins. In Lactins V (Bog-Hansen TC, Driessche EV, eds.) Walter de Gruyter and Co., Berlin, pp. 221-228.

Kolb H, Vogt D, Herbertz L, Corfield Al, Schauer R, Schlepper -Schafer $J$ (1980). The galactose-specific lectins on rat hepatocytes and Kupffer cells have identical binding characteristics. Hoppe-Seyler's Z. Physiol. Chem., 361: 1747-1750.

Kolb H, Kolb-Bachofen V (1978). A lectin - like receptor on mammalian macrophage. Biochem. Biophys. Res. Comm., 85: 678-683.

Kuster JM, Schauer R (1981). Phagocytosis of sialidase-treated rat erythrocytes: Evidence for a two-step mechanism. Hopper-Seyler's Z. Physiol. Chem., 361: 1507-1514.

Muller E, Schroder C, Schauer R, Sharon M (1983). Binding and phagocytosis of sialidase treated rat erythocytes by a mechanism independent of opsonins. Hopper-Seyler's Z. Physiol. Chem., 364: 1419-1429.

Muller E, Franco MW, Schauer R (1981). Involvement of membrane galactose in the in vivo and in vitro sequestration of desialylated erythrocytes. Hopper-Seyler's Z. Physiol. Chem., 362: 1615-1620.
Nagamura Y, Kolb H (1979). In: Glyco-conjugates (Schauer R, Boer P, Buddecke E, Kramer MF, Vliegenthart JFG, Weigaudt $H$ eds.) Verlag G. Thieme, Stuttgart., p. 490.

Nok AJ, Uemura A (1998). The T. b. rhodesience. Parasitol. Int., 88: 56.

Pereira MEA (1983). A developmentally regulated neuraminidase activity in T. cruzi. Science, 219: 1444-1449.

Pereira MEA, Hoff R (1986). Heterogeneous distribution of neuraminidase activity in strains and clones of $T$. cruzi and its possible association with parasite myotropism. Mol. Biochem. Parasitol., 20: 183-189.

Schenkman S, Eichiger DT (1993). Trypanosoma cruzi transsialidase and cell invasion. Parasitol. Today, 9: 218-225.

Schlepper-Schafer J, Kolb-Bachofen V, Kolb H (1980). Analysis of lectin-dependent recognition of asialo-erythrocytes by Kupffer cells. Biochem. J., 186: 827-831.

Shugaba A, Umar I, Omage JJ, Ibrahim NDG, Andrews J, Ukoha Al, Saror DI, Esievo KAN (1994). Biochemical differences (O-Acetyl and Glycolyl groups) in erythrocyte surface sialic acids of trypanotolerant N'dama and trypanosusceptible Zebu cattle. J. Comp. Pathol., 110: 91-95.

Umar IA, Ameh DA,Esievo KAN (1998a). Normal plasma lactose concentrations and kinetics of intravenously infused lactose in cattle. Res. Vet. Sci., 65: 1-4.

Umar IA, Sadiq GS,Esievo KAN (2003). The effect of $T$. congolense infection on free and membrane-bound sialic acid levels in blood and tissue of rabbits. Niger. J. Biochem. Mol. Biol. 18(1): 43-46.

Umar IA, Omage JJ, Shugaba A, Igbokwe IO, Ibrahim NDG, Kadima KB, Ameh DA, HO Kwanashie RIS, Agbede, Saror DI, Esievo KAN (1998b). Effects of acute bovine trypanosomiasis ( $T$. vivax) on plasma kinetics of intravenously administered lactose. Vet. Parasitol., 74: 173-178.

Woo PTK (1969). The haematocrit centrifuge technique for detection of trypanosomes in blood. Can. J. Zool., 47: 921-923. 